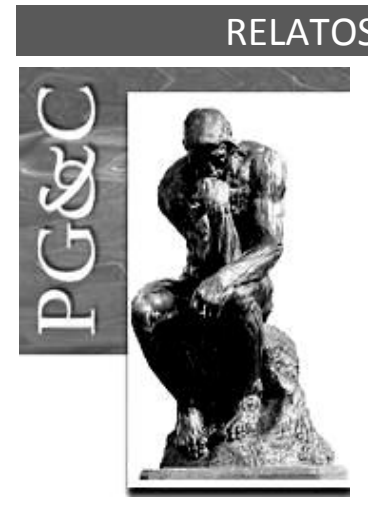

\title{
ABORDAGENS DA LIDERANÇA NAS FASES DA GESTÃO DO CONHECIMENTO: UMA ANÁLISE EVOLUTIVA
}

\author{
Micheline Guerreiro Krause \\ Doutoranda em Engenharia e Gestão do Conhecimento pela Universidade \\ Federal de Santa Catarina, Brasil. \\ E-mail: michelinekrause@gmail.com \\ Cristiano José Castro de Almeida Cunha \\ Doutor em Administração de Empresas pela Rheinisch-Westfalische \\ Technische Hochschule Aachen, Alemanha. Professor da Universidade \\ Federal de Santa Catarina, Brasil. \\ E-mail: 01cunha@gmail.com
}

\section{Gertrudes Aparecida Dandolini}

Doutora em Engenharia de Produção pela Universidade Federal de Santa Catarina, Brasil. Professora da Universidade Federal de Santa Catarina, Brasil. E-mail: ggtude@gmail.com

\begin{abstract}
Resumo
A liderança é um dos pilares da gestão do conhecimento, sendo ao mesmo tempo produtora e produto da cultura organizacional. $O$ objetivo deste estudo é estabelecer relações entre a evolução das abordagens da liderança com as fases históricas da gestão do conhecimento (GC), considerando a alteração gradativa da cultura organizacional. 0 procedimento metodológico foi o de revisão narrativa da literatura, com coleta não sistemática dos dados em fontes físicas e em bases indexadoras digitais. As análises foram conduzidas pela questão de pesquisa proposta. Os resultados revelam alinhamento entre as abordagens de liderança e as fases de gestão do conhecimento. Na fase de GC caracterizada como da comunicação, a principal abordagem de liderança evidenciava a espetacularização dos líderes, com exploração de estereótipos, imagem e traços dos grandes homens. Na fase de informatização, as abordagens de liderança evoluíram para o enfoque nas habilidades, nos comportamentos, nos estilos, na definição de caminho-objetivo, contingências, treinamentos, orientação para as tarefas, relacionamentos e participação na vida organizacional. Na fase da virtualização, que preconizava a necessidade de significativas mudanças culturais, as abordagens evidenciavam a liderança transformacional, a motivação humana, o empoderamento, desenvolvimento dos colaboradores, estabelecimento de trocas e conexões, autoconhecimento e espiritualidade no ambiente de trabalho. $\mathrm{Na}$ fase de personalização, as abordagens evidenciavam a liderança complexa, as competências complementares, o processo dinâmico e emergente, o enfoque em comunicação, criatividade, aprendizagem, integração e harmonização das diferentes perspectivas, em um processo de customização da própria liderança.
\end{abstract}

Palavras-chave: Gestão do Conhecimento. Abordagens da Liderança. Cultura Organizacional. Revisão Narrativa.

Perspectivas em Gestão \& Conhecimento, João Pessoa, v. 8, número especial, p. 39-54, out. 2018 DOI: http://dx.doi.org/10.21714/2236-417X2018v8nep39

http://periodicos.ufpb.br/ojs2/index.php/pgc. ISSN: 2236-417X. Publicação sob Licença (cc)) EY-Nc-ND 


\title{
LEADERSHIP APPROACHES IN THE PHASES OF KNOWLEDGE MANAGEMENT: AN EVOLUTIONARY ANALYSIS
}

\begin{abstract}
Leadership is one of the pillars of knowledge management, being at the same time producer and product of organizational culture. The objective of this study is to establish relations between the evolution of leadership approaches and the historical phases of knowledge management (KM), considering the gradual change in organizational culture. The methodological procedure used to this end was the narrative review of the literature with non-systematic data collection on physical and digital database sources. The analyzes were driven by the proposed research question. The results reveal alignment between leadership approaches and the phases of knowledge management. In the KM phase characterized as communication the main leadership approach evidenced the spectacular representation of leaders, exploration of stereotypes, image and traits of great men. In the phase of computerization the leadership approaches evolved to focus on skills, behaviors, styles, definition of path-goal, contingencies, training, orientation to tasks, relationships and participation in organizational life. In the virtualization phase, which advocated the need of significant cultural changes, the approaches evidenced transformational leadership, human motivation, empowerment, employee development, establishment of exchanges and connections, as well as seeking self-awareness and spirituality in the workplace. In the KM phase identified as personalization, the approaches revealed complexity leadership, the need to gather complementary competencies, dynamic and emergent process management, focus on communication, creativity, learning, integration and harmonization of the different perspectives, in a process of customization of the leadership itself.
\end{abstract}

Keywords: Knowledge management. Leadership approaches. Organizational culture. Narrative review.

\section{INTRODUÇÃO}

A gestão organizacional ocorre em um tempo e espaço permeado por valores culturais, sociais e econômicos, que atuam na construção da realidade. Esta não ocorre em um vácuo, mas dentro de um contexto histórico que deve ser analisado. A gestão do conhecimento pode ser vista como um processo de revelação e utilização de conhecimentos relevantes para a identificação de padrões, tendências e compreensão do contexto vivenciado nas organizações.

As tendências organizacionais podem ser intencionalmente correlacionadas com as fases de Gestão do Conhecimento (GC), na busca de compreensões sobre o alinhamento e convergência interdisciplinar. Por interdisciplinaridade compreende-se a "forma de produção do conhecimento que implica trocas teóricas e metodológicas, geração de novos conceitos e metodologias e graus crescentes de intersubjetividade" (AVALIAÇÃO, 2016).

Wiig (2004) distingue a existência de uma nova geração de GC, mais integrada à filosofia, estratégias, práticas organizacionais e mais integrada ao cotidiano dos colaboradores. A visão sublinha uma perspectiva de $\mathrm{GC}$ que reconhece o papel do elemento humano como essencial nas organizações, uma vez que todos os outros ativos são resultados das ações humanas (SVEIBY, 1998), inclusive as infraestruturas tecnológicas.

Neste contexto, o papel das lideranças é evidenciado na gestão do conhecimento, sendo um de seus pilares (STANKOSKY, 2005). Ao revisar a literatura, Krause (2014) verifica a relevância do papel das lideranças em implementações de GC, transpassando os demais pilares, como cultura, pessoas e processos, uma vez que atua como promotora ou inibidora da mobilização dos colaboradores. A liderança é um fenômeno universal e a própria história das civilizações traz consigo a história de líderes, no papel de reis, governantes, faraós (BASS, 1990), ou de homens visionários que promovem mudanças na sociedade.

Perspectivas em Gestão \& Conhecimento, João Pessoa, v. 8, número especial, p. 39-54, out. 2018. 
A literatura sobre liderança revela como as suas abordagens foram sendo modificadas, de acordo com o conjunto das circunstâncias vigentes. Schein (2004) atribui à liderança a capacidade de mudar e criar uma nova cultura, e à gestão ou administração a necessidade de manter a cultura já estabelecida. Já Heifetz (1994) atribui à liderança a função de trabalho adaptativo, que atenda aos valores e contexto de uma sociedade democrática. Na avaliação do autor, a compreensão sobre liderança teve uma evolução no mundo dos negócios, deixando de ser relacionada exclusivamente a altas posições de gestão, para ser mais relacionada ao exercício de promover visões e influências não coercitivas. $O$ trabalho adaptativo diz respeito a interpretar a realidade, suprir as falhas, aprender novas formas, ajustar cultura, conciliar crenças, administrar desafios, considerar a variedade de valores (HEIFETZ, 1994).

Diante desta visão inter-relacionada, a motivação para o desenvolvimento do presente estudo tem como principal indagação de pesquisa: como as abordagens da liderança evoluíram em relação às fases históricas da gestão do conhecimento, considerando-se a cultura organizacional? O principal objetivo do estudo é estabelecer relações entre a evolução das abordagens da liderança com as fases históricas da gestão do conhecimento, considerando a alteração gradativa da cultura organizacional. Para tanto, o método utilizado foi o de revisão narrativa da literatura.

\section{REFERENCIAL TEÓRICO}

A liderança é uma atividade, que envolve mobilizar pessoas, e que pode ser vista como um trabalho adaptativo, com mudanças em valores, crenças e comportamentos (HEIFETZ, 1994). Na avaliação desse autor, os processos adaptativos podem atuar em nível inconsciente. Ele considera que um indivíduo pode melhorar a sua capacidade adaptativa ao melhorar sua capacidade de refletir sobre os eventos e circunstâncias. Ao abordar a questão da definição de liderança, Heifetz (1994) sugere levar em consideração a relação com os pressupostos culturais, a praticidade, a relevância e ampla utilidade social.

Northouse $(2013$, p. 5). Define que a "liderança é um processo em que um indivíduo influencia um grupo de indivíduos para alcançar um objetivo comum". Ao considerar a liderança como um processo, o autor busca expandir seu escopo, não associando a prática a um líder formalmente designado, visto que um líder pode exercer influência sobre as pessoas devido às suas características e forma de atuação (GRAMKOW, 2016).

As variadas abordagens de liderança enfocam diferentes aspectos, valores, visão de mundo ou distintos contextos da gestão organizacional. Uma das primeiras abordagens identificadas na literatura é a abordagem dos traços, com enfoque na entidade. Uma das mais atuais é a relacional, com enfoque em processos contínuos de construção social. Bass (1990) afirma que liderança é um fenômeno universal, fazendo parte da própria história da humanidade. A liderança compõe um dos quatro pilares de GC, juntamente com os processos de organização, tecnologias e aprendizagem (STANKOSKY, 2005).

O conhecimento pode ser compreendido como "[...] o conjunto completo de informações, dados, relações que levam as pessoas a tomar decisões, a desempenhar atividades e a criar novas informações ou conhecimentos" (MACEDO et al., 2010, p. 40). 0 conhecimento impacta a tomada de decisões e atividades organizacionais, além de oferecer a base para a criação de novos conhecimentos, práticas, atitudes e tendências.

Já a gestão do conhecimento é "o processo de criar continuamente novos conhecimentos, disseminando-os amplamente através da organização e incorporando-os velozmente em novos produtos/serviços, tecnologias e sistemas" (TAKEUCHI; NONAKA, 2008, p. IX). A implementação das práticas e processos de GC requer alinhamento estratégico, enfoque em pessoas, cultura favorável, incorporação do conhecimento no "tecido" das

Perspectivas em Gestão \& Conhecimento, João Pessoa, v. 8, número especial, p. 39-54, out. 2018. 
empresas, conforme elucidado por Dalkir (2005), bem como modificação de comportamento (DUBOIS; WILKERSON, 2008).

De acordo com Dalkir (2005), o ambiente cultural de uma organização é determinante para o desenvolvimento da gestão do conhecimento. A cultura pode ser compreendida como os valores, crenças, comportamentos, práticas e significados compartilhados que diferenciam uma comunidade ou sociedade (DALKIR, 2005), envolvendo um conjunto de símbolos, artefatos e elementos materiais. A autora explica, ainda, que organizações são constituintes da sociedade e empregam pessoas que trazem com elas o arcabouço cultural das redondezas. Ao mesmo tempo, porém, as organizações podem estar à parte da cultura local, uma vez que estabelecem suas próprias regras, valores, forma de agir e de se organizar. Neste sentido, Baldissera $(2009$, p. 136) considera que organizações são ao mesmo tempo produto e produtoras da sociedade, ou seja, tanto resultado quanto construtoras da teia sociocultural. $\mathrm{Na}$ visão do autor, "os sujeitos transformam o entorno que os transforma - constroem a sociedade que os constrói - em permanentes processos de (des/re)organização".

A cultura recebe diferentes definições, por ser um termo abstrato e utilizado em várias áreas do conhecimento. A cultura é compreendida como um conjunto compartilhado de qualidades diferenciadoras, bem como um conjunto de "crenças, valores, regras, normas, símbolos e tradições que são comuns a um grupo de pessoas" (NORTHOUSE, 2013, p. 384, tradução nossa). A cultura é um fenômeno vivo por meio do qual as pessoas criam e recriam o mundo em que vivem (MORGAN, 1980).

A cultura organizacional reúne um conjunto de padrões e suposições básicas desenvolvidas por grupos em relação às circunstâncias vivenciadas de adaptação e integração do meio interno ao externo, e que devem ser transmitidas aos novos membros, a fim de orientar percepções, pensamentos e resoluções de problemas (SCHEIN, 2004). A cultura organizacional pode ser considerada tanto como causa como efeito, e pode exercer influências nas pessoas sem que elas se tornem conscientes (DALKIR, 2004). Ao revisar a literatura, Dalkir (2004) identifica que a cultura perpassa tanto os aspectos visíveis organizacionais, como as estruturas e processos, quanto valores, visões, concepções, percepções e sentimentos.

\section{PROCEDIMENTOS METODOLÓGICOS}

O procedimento metodológico empregado foi o da revisão narrativa da literatura, conduzida de forma interpretativa. A fim de aumentar a possibilidade de uma revisão significativa e de alta qualidade, o processo de revisão foi orientado pela questão de pesquisa. De acordo com Forbes (2003), a elaboração de questão de pesquisa oferece direção, guia o processo, determina o foco para a extração dos dados. Com base em Torraco (2005), a revisão examinou a literatura com uma lente particular definida pelo objetivo.

A revisão da literatura é uma ferramenta essencial para lidar com a variedade de conhecimentos nas investigações acadêmicas, mapear e avaliar o território, bem como responder a uma pergunta específica que conduza ao desenvolvimento de novos conhecimentos (TRANFIELD, DENYER; SMART, 2003). De acordo com esses autores, a revisão narrativa é mais suscetível de apresentar viés que a sistemática, porém, é a forma mais simples para identificar o que foi escrito sobre o assunto. A escolha se deve pela necessidade de exploração ampla dos dados, considerando as várias fontes e os vários termos das abordagens da liderança, o que tornaria exaustivo o detalhamento do processo sistemático.

A coleta dos dados envolveu buscas e seleção de artigos de periódicos revisados por pares, capítulos de livros, teses e dissertações, buscas de referências utilizadas pelos autores consultados, de forma aleatória e não sistemática. Além do material físico, bases de dados eletrônicos foram utilizados, com busca aos variados termos relacionados às fases históricas

Perspectivas em Gestão \& Conhecimento, João Pessoa, v. 8, número especial, p. 39-54, out. 2018. 
de GC e às abordagens de liderança. Os estudos foram avaliados independentemente, por uma revisora, e codificados com base no alinhamento à questão de pesquisa proposta.

\section{ANÁLISE DO PROCESSO DE COEVOLUÇÃO}

Esta seção apresenta a linha condutora do desenvolvimento das fases históricas da gestão do conhecimento (DALKIR, 2005), e estabelece paralelos com as várias abordagens de liderança. Ao final, visualização do conhecimento é oferecido por meio de figura de síntese.

Prévia exploração da literatura sobre liderança identificou que a primeira abordagem surgiu nos anos de 1900, fase identificada como da comunicação. Desta forma, foram suprimidos os dados referentes às fases anteriores, referentes às fases da industrialização e dos meios de transporte.

\subsection{Fase da comunicação}

A comunicação no início do século 20 presenciou a passagem de uma sociedade baseada na oralidade para uma sociedade mobilizada pelos meios de comunicação de massa. De acordo com Martino (2013), a eclosão das mídias impactou a dinâmica da sociedade e as relações entre pessoas e instituições, tendo ampla adesão do público norte-americano, fascinado pelo rádio, pelas notícias e pelo cinema.

A indústria cinematográfica de Hollywood promoveu a cultura das celebridades, já na primeira década dos anos de 1900, o que levou à figuração do indivíduo como mercadoria, e à visibilidade de "atores personagens de si mesmos", com carisma suficiente para virar uma atração (MARTINO, 2013, p. 162). De acordo com esse autor, a ideia de mercadoria-imagem foi articulada por Walter Benjamin, no "trabalho das passagens", em alusão às vitrines de uma luxuosa galeria no Centro de Paris. Estabelecia-se uma nova relação entre as pessoas, a mercadoria e a cultura, visto que "na vitrine não se expõe qualquer produto: deve ser bonito. Deve ter uma imagem" (MARTINO, 2013, p. 60).

Debord (2005) analisa que a vida nas sociedades onde prevalecem as condições modernas de produção gira em torno da acumulação de espetáculos, compreendidos tanto como resultado quanto como projeto de produção de imagens nas relações sociais. Desta forma, "a realidade surge dentro do espetáculo, e o espetáculo é real" (DEBORD, 2005, p. 9, tradução nossa), como algo grandioso, positivo e indiscutível, em um domínio da aparência e do fetichismo exercido pela mercadoria, mesmo que esta mercadoria seja uma pessoa, explorada como imagem heróica admirável e passível de projetar identificação.

Em 1922, o jornalista e pesquisador Walter Lippman destaca a influência da mídia na criação de estereótipos, na obra intitulada Public Opinion. Para Martino (2013), estereótipos são imagens mentais construídas por indivíduos a partir de traços previamente identificados. A palavra estereótipo tem sua origem no processo de impressão, em que um molde é feito e replicado em placa de metal que oferece rigidez e reprodução. Estereótipos podem ser vistos como imagens ou generalizações exageradas de traços fisiológicos, biológicos, características ou padrões de comportamento atribuídos a indivíduos e coletividades (CURTIS, 1998).

Para Lippmann (1998), os estereótipos representam a garantia de projeções, sentidos, valores, e autoimagem, e apresentam pessoas reais cujas personalidades são construídas. 0 autor faz paralelo com a sociedade norte-americana, onde as visões são orientadas pela imagem de pessoas bem-sucedidas, grandiosas, capazes de grandes feitos e responsáveis pelo progresso da nação. Lippmann afirma que a pessoa define suas percepções, inconsciente e antecipadamente, com base nos estereótipos vigentes, nas tradições, nível de conforto com a situação, adaptabilidade e manutenção das expectativas sobre os papéis desempenhados na sociedade. Há um contexto propício para a manipulação do repertório de estereótipos, em que

Perspectivas em Gestão \& Conhecimento, João Pessoa, v. 8, número especial, p. 39-54, out. 2018. 
a utilização de símbolos pode ser uma alavanca que líderes utilizam para mover a coletividade, promover identificação, vocalizar a opinião da maioria, contar boas histórias e fazer de si mesmo uma marca (LIPPMANN, 1998).

Nesse contexto de início do século 20 , surge na literatura a abordagem dos traços, que evidenciava os traços e personalidades dos grandes homens. Os estudos compreendidos por Stogdill no período de 1904 a 1947 revelaram que pessoas em cargos de liderança apresentavam características distintas, dentre elas a autoconfiança, inteligência, perspicácia, popularidade, fluência verbal, integridade, determinação, sociabilidade, adaptabilidade às situações (BASS, 1990; NORTHOUSE, 2013), bem como habilidades atléticas e traços físicos associáveis aos padrões de beleza vigente. Essas características se enquadravam em seis principais critérios, sendo eles o status, a participação, a realização, a capacidade, a responsabilidade, e as habilidades situacionais (BASS, 1990). O enfoque dessa abordagem reside nas qualidades e traços natos de pessoas nascidas já com as características e capacidades para liderar (NORTHOUSE, 2013) e serem vistas como notórias personalidades.

Cada revisão da literatura nos anos subsequentes, no entanto, revelaram outros conjuntos de características, o que demonstrou inconsistências, ambiguidades e multiplicidade de traços, o que demonstrou que a abordagem não deveria ser evidenciada como absoluta (BASS, 1990; NORTHOUSE, 2013). Curiosamente, a própria literatura sobre comunicação aponta que os estereótipos não resistem ao contato com a realidade de forma mais profunda (MARTINO, 2013) ou de forma mais consciente sobre as tendenciosidades de percepção.

\subsection{Fase da informatização}

O advento da era dos computadores, nos anos de 1950, promoveu a informatização e o valor de ativos relacionados ao conhecimento, à aprendizagem organizacional, ao repositório de informações corporativas, comunicação, troca de mensagens, valoração de especialistas e das habilidades de codificação (DALKIR, 2005). As tecnologias computacionais permitiram que os conhecimentos pudessem ser armazenados como memória corporativa prontamente disponível, aplicável e acessível a diferentes públicos. A fase foi impulsionada pelo lançamento da Arpanet, em 1969, que permitiu a rápida comunicação entre cientistas e pesquisadores e troca de significativas quantidades de dados. De acordo com Dalkir (2005), a fase favoreceu o desenvolvimento dos sistemas baseados em conhecimento, como os sistemas de tutoria inteligente e a inteligência artificial.

Por volta dos anos de 1950, prévias inovações tecnológicas de automação já haviam modificado as categorias de trabalho. A informatização, porém, teve como diferencial a habilidade de vinculação das várias fases de produção ao sistema computacional, de forma multifuncional e reprogramável, de forma flexível e adaptável às necessidades emergentes do processo de produção (GIORDANO, 1992).

Nas primeiras décadas da informatização, não houve imediata mudança nas relações de trabalho (LAVOIE; THERRIEN, 2005), pois poucas organizações possuíam processos computadorizados. Surgiam, porém, as primeiras questões contingenciais sobre as mudanças e impactos que acarretariam nos negócios, na qualidade, no comportamento dos trabalhadores, verificando-se que as respostas dependiam do tipo de negócio e ocupação (KLING, 2000). Gradativamente, a mão de obra manual e qualificada foi sendo substituída por mão de obra técnica e com habilidades específicas, inicialmente nos setores da indústria química e de processamento de alimentos (GIORDANO, 1992), dentre outros.

Contrariando a predição corrente nos anos de 1950, de que a computadorização conduziria ao desemprego em massa, o que ocorreu foi a complementaridade e substituição, com menor demanda para ocupações de alto esforço físico e maior demanda de ocupações com habilidades mentais. A introdução da informatização promoveu a complementaridade

Perspectivas em Gestão \& Conhecimento, João Pessoa, v. 8, número especial, p. 39-54, out. 2018. 
entre o conhecimento, a gestão e as habilidades em trabalhar com dados, de forma contingencial com as necessidades tácitas ou codificáveis (LAVOIE; THERRIEN, 2005).

$O$ impacto mostrava-se contingente também em relação às relações sociais estabelecidas na empresa, uma vez que a estrutura organizacional e a reorganização técnica assumiam a compreensão de que "a tecnologia influencia e é influenciada por fatores sociais", dentre eles o nível de habilidades dos trabalhadores e a natureza da indústria e de seus mercados (GIORDANO, 1992, p. 200, tradução nossa). De acordo com a autora, a informatização passou a afetar tanto o processo de produção quanto o produto, definindo o que devia ser produzido, as rápidas mudanças no mercado e os métodos utilizados.

Progressivamente, operações e tarefas foram absorvidas pela tecnologia, começando pela automação e simplificação das tarefas manuais, favorecimento de novos conhecimentos de codificação, consciência da interdependência e colaboração entre os empregados, trabalho em equipes, bem como participação de trabalhadores em sistemas de autogestão da própria produtividade e eficiência (GIORDANO, 1992). O ambiente organizacional passou a ser visto como global, em rápida mudança e precisando administrar bem a profusão de informações. Surge a necessidade de desenvolver "habilidades de alfabetização informacional", diante da demanda por trabalhadores que soubessem identificar, localizar, selecionar, avaliar, utilizar e aplicar adequadamente as informações (ALA, 1989).

Paralelamente, por volta dos anos de 1950, a literatura sobre liderança se apoiava nos estudos de Stogdill, de 1948, para enfatizar a abordagem dos estilos, com enfoque em como os líderes agiam e se comportavam para influenciar seus subordinados a alcançarem os melhores resultados (NORTHOUSE, 2013). Três principais tipos de comportamento se destacavam, de acordo com Yukl (2006): a) os comportamentos orientados para as tarefas, em que líderes se concentravam no planejamento, coordenação do trabalho, fornecimento de equipamentos, assistência e suporte aos subordinados, bem como condução para o estabelecimento de metas alcançáveis de desempenho; b) os comportamentos orientados para os relacionamentos baseados em confiança, compreensão, consideração, atenção ao desenvolvimento da carreira dos subordinados, atenção às suas ideias, autonomia e reconhecimento de seus esforços e resultados; e c) os comportamentos facilitadores de participações, em que líderes incentivam seus liderados na tomada de decisões, resolução de conflitos, cooperação e nos processos de comunicação (YUKL, 2006).

Em 1955, Katz (1974, apud NORTHOUSE, 2013) propunha a abordagem das habilidades, centrada nos líderes e em suas três principais competências e habilidades, sendo elas: as habilidades técnicas especializadas de análise, aplicação de métodos e processos de produção; as habilidades humanas para o trabalho em equipe, cooperação, confiança, empatia, adaptabilidade ao outro e comunicação; e as habilidades conceituais, com o enfoque em visão, estratégia, sistema, compreensão da relação com a comunidade e com o contexto. $\mathrm{Na}$ abordagem das habilidades, indivíduos podem ser desenvolvidos para exercer a liderança, com enfoque em aprendizagem e proveito das experiências (MUMFORD et al., 2000).

Em torno de 1964 surge a teoria da contingência, com enfoque na combinação do estilo do líder ao contexto de atuação (FIEDLER, 2006). Dois principais comportamentos são considerados: o motivado por tarefas e objetivos; ou por relacionamentos e desenvolvimento das relações interpessoais. O enfoque relaciona estes comportamentos com as variáveis situacionais caracterizadas pelas boas relações entre líderes e liderados, pela estrutura, clareza e delegação de tarefas, e pelo poder e autoridade exercida na posição como líder.

Ao final da mesma década, no ano de 1969, surge a abordagem situacional, sendo muito utilizada em treinamentos e desenvolvimento organizacional, conforme verifica Northouse (2013). O enfoque reside na adaptabilidade do líder às diferentes situações, em que atua de forma diretiva ou de forma a oferecer suporte, em resposta à atuação dos liderados. Nesta abordagem, são evidenciados o estilo diretivo, que envolve supervisão e comunicação

Perspectivas em Gestão \& Conhecimento, João Pessoa, v. 8, número especial, p. 39-54, out. 2018. 
de instruções; o de coaching direcionador e de encorajamento socioemocional; o estilo de suporte, incentivo e reconhecimento das competências dos liderados; e o estilo de delegação, em que o líder demonstra ter confiança nas responsabilidades dos liderados.

No início da década seguinte, a partir do ano de 1970, a literatura aborda a teoria do caminho-objetivo, cujo enfoque verifica como os líderes motivam seus liderados para que atinjam os objetivos, tenham bom desempenho e satisfação no trabalho (NORTHOUSE, 2013). O autor explica que a teoria leva em consideração tanto o estilo do líder quanto as características dos liderados, bem como o contexto estrutural da organização. Como o próprio nome sugere, os principais aspectos podem ser resumidos em definir os objetivos, apresentar caminhos, remover obstáculos, e oferecer suporte.

Ainda nos anos de 1970, Robert Greenleaf propõe o conceito de liderança servidora, em que líderes enfocam as necessidades e preocupações dos liderados e os ajudam a desenvolver suas capacidades pessoais. A liderança atua de forma ética, responsável e de modo a priorizar os colaboradores, a organização, a comunidade e a própria sociedade (YUKL, 2006; NORTHOUSE, 2013).

Fechando a fase da informatização, a literatura sobre liderança presencia, também na década de 1970, o surgimento da teoria da troca líder-liderado, conhecida como leadermember exchange (LMX), com enfoque nas trocas e interações entre os envolvidos. A teoria passa por distintos estágios, enfatizando primeiramente as relações diádicas dentro de uma mesma unidade de trabalho, para em seguida enfatizar o escopo organizacional, passando para a ênfase na visão de processo e de construção da liderança, e progredindo para a ênfase na visão de coletividade, que prioriza a construção de times de trabalho e redes de competências (GRAEN; UHL-BIEN, 1995).

\subsection{Fase da virtualização}

Uma década após o estabelecimento da internet, surgiram as primeiras evidências de comunidades virtuais, conforme verifica Dalkir (2005). Isto ocorreu no início dos anos de 1980, após o lançamento de uma rede denominada Usenet, que intencionava distribuir e compartilhar dados técnicos e objetivos entre pesquisadores e que deu origem aos primeiros agrupamentos de pessoas que compartilhavam assuntos de interesse geral (DALKIR, 2005).

As organizações virtuais são caracterizadas pela descentralização, flexibilidade, adaptabilidade às mudanças, estruturas horizontalizadas e em rede, pela comunicação e coordenação dos processos internos (LEMKEN; KAHLER; RITTENBRUCH, 2000). Esses autores afirmam que o advento das organizações virtuais enfatizou a necessidade de formar equipes com capacidades, conhecimentos e características que atendessem às tarefas específicas de cada projeto, e que tivesse o comprometimento dos membros.

O valor à construção de cultura organizacional é evidenciado e, "dentro dessa cultura, é necessário que cada indivíduo siga seu próprio caminho de desenvolvimento, o que é na verdade o núcleo do funcionamento das organizações virtuais" (DALKIR, 2005, p. 200, tradução nossa). Cabe interpretar que surgem significativos desafios relacionados à mudança de cultura, com necessidades de adaptações, novos treinamentos, desenvolvimento do valor ao compartilhamento de informações e conhecimentos (ALA, 1989).

Lemken, Kahler e Rittenbruch (2000) enfatizam, ainda, a importância dos relacionamentos dos membros entre si e com a organização, a qualidade do trabalho, motivação, coesão dos membros na direção de objetivos comuns, compartilhamento de valores e identidade organizacional, bem como uma forte cultura organizacional baseada em compartilhamentos, confiança mútua, transparência e participação na construção organizacional. $\mathrm{Na}$ era da virtualização, a presença social foi enfatizada, bem como a percepção de identificação e de pertencimento, visto que as pessoas precisam perceber a

Perspectivas em Gestão \& Conhecimento, João Pessoa, v. 8, número especial, p. 39-54, out. 2018. 
presença de outros, as conexões e correspondências nas interações (DALKIR, 2005). De acordo com essa autora, as conversações formais ou informais tornaram-se parte essencial da era da virtualização, sendo consideradas como um processo social fundamental, em que as pessoas se retratam, revelam seus estilos, suas agendas, suas capacidades e profissionalismo.

Ao revisar a literatura, Franke (2000) evidencia as seguintes características das corporações virtuais: a possível temporalidade de parceria, o envolvimento concomitante em outras parcerias, a manutenção do próprio cotidiano e independência, responsabilidades de riscos e custos, compartilhamento de recursos e de acesso a novos mercados, integração das cadeias de valores, parceria com empresas rivais, inclusão de pequenas e médias organizações no mercado global junto às grandes corporações, voluntariado, bem como a cooperação, confiança, fluidez e flexibilidade. As organizações envolvidas podem estar ancoradas em uma teia virtual, cujas características incorporam o critério de pré-qualificação, cultura e desenvolvimento de confiança, busca virtual por parceiros, rápida formação, rápida operação, e sistema de penalidades em relação à reputação. A comunicação é vista como facilitadora na coordenação de atividades entre os parceiros e como geradora de conhecimentos que levam à inovação de produtos e serviços (FRANKE, 2000).

Em paralelo, nos anos de 1980, a literatura sobre liderança abordava a liderança transformacional, que enfoca o processo de mudar, transformar as pessoas, motivá-las à superação das expectativas e a colocar o bem coletivo acima de seus interesses individuais (BASS, 1990). Esta abordagem envolve o carisma ou influência idealizada, a inspiração motivada pela comunicação e por apelos emocionais, a estimulação intelectual, a atenção e apoio às necessidades dos liderados. De acordo com Northouse (2013), a liderança transformacional está relacionada a valores morais, ética, empoderamento, desenvolvimento pessoal e coletivo. Afirma, também que os envolvidos transformam-se mutuamente, estabelecem conexões, inspiram uns aos outros.

Concomitantemente, por volta dos anos de 1980, surge a liderança transacional que, como o nome sugere, foi caracterizada pelas trocas transacionais envolvendo líderes-liderados (NORTHOUSE, 2013). Nela, os fatores evidenciados são as recompensas contingenciais específicas ao esforço do liderado, o gerenciamento com base em correção, feedback e controle, conforme pontua o autor. Surge, também, a liderança carismática, às vezes confundida com a transformacional, visto que líderes carismáticos são considerados inspiradores, com comportamento e personalidade especiais, e como modelos a serem seguidos (HOUSE, 1976 apud NORTHOUSE, 2013). Em adição, o período identificou a liderança autêntica, com enfoque na autenticidade do líder, no seu caráter, seu autoconhecimento, transparência, relações intrapessoais e interpessoais, bem como o enfoque nas influências mútuas, conforme listado por Northouse (2013).

Na década de 1990, a era eletrônica global e multicultural fez emergir a atenção à totalidade e espiritualidade das pessoas no ambiente de trabalho, visto que este crescia em importância em suas vidas, sendo fonte de valores sociais, significados e percepção de pertencimento a uma comunidade (FAIRHOLM, 1998). Fazia-se necessário estabelecer e manter a saúde e o vigor corporativo dos trabalhadores, a energia cooperativa entre as unidades, adicionando-se valor espiritual em um contexto de técnicas e sistemas. De acordo com esse autor, a liderança espiritual reflete a crescente demanda por trabalhadores com desenvolvidas habilidades e competências, em superação às qualidades utilizadas nas linhas de montagem. "O desafio para os líderes é encontrar uma nova linguagem do espírito", que dê sentido e significado às vidas das pessoas, e use essa linguagem para moldar a corporação, sua atuação nela e o próprio conceito de liderança (FAIRHOLM, 1998, p. 95, tradução nossa). Na visão desse autor, líderes são vistos como professores, desenvolvedores, inspiradores de novos valores normatizadores e como fontes de informação e conhecimento. Ele propõe, ainda, um esquema com oito principais ideias elencadas pela liderança espiritual: definição de visão,

Perspectivas em Gestão \& Conhecimento, João Pessoa, v. 8, número especial, p. 39-54, out. 2018. 
prontidão servidora, competência de tarefa, construção de comunidade, alto padrão moral, integridade, administração atenta, e melhoria contínua.

\subsection{Fase da personalização}

$\mathrm{Na}$ fase de personalização, evidencia-se a busca em corresponder às necessidades dos usuários, com ênfase em um modelo de troca que possibilite ganhos mútuos (DALKIR, 2005). De acordo com a autora, esta fase enfatiza a importância do contexto, do repositório de conhecimentos, identificação de atributos e disponibilização de conteúdo adequável às preferências de diferentes clientes e integrado às rotinas organizacionais. As interações envolvendo humanos e não humanos são evidenciadas nesta fase, com valor à compreensão das preferências e comportamentos interativos dos usuários, e enfoque em comunicação. Para Dalkir (2005), um dos fatores mais importantes a serem considerados é o processo de modelagem por parte do usuário, em uma adaptação contínua em relação às mudanças individuais, organizacionais e ambientais, bem como o processo de aplicação e internalização do conhecimento, com base no comportamento observado e analisado da pessoa e de grupos de pessoas que compartilham afinidades.

A personalização pode ser vista como uma atividade interativa do marketing, e estabelece relações com a customização, apesar de haver distinções entre elas, conforme pontuam Montgomery e Smith (2009). Para esses autores, a personalização é mais refinada, visto que pode ser intencionalizada por profissionais de marketing em benefício de clientes, enquanto a customização é requisitada pelos clientes em função de benefício próprio. Eles definem personalização como "a adaptação de produtos e serviços pelo produtor para o consumidor usando informações que foram inferidas do comportamento ou de transações do consumidor", em um processo em que a tecnologia serve como facilitadora, tanto no sentido de criar as adaptações, se comunicar com o consumidor, coletar informações ou fazer inferências sobre o consumidor (MONTGOMERY; SMITH, 2009, p. 130, tradução nossa). Eles esclarecem que a personalização precede a internet, mas que esta última a favorece.

Uma das preocupações da personalização é com o conhecimento tácito e sua transferência, pela facilitação da interação entre as pessoas. A personalização favorece a criatividade, inovação de produtos e serviços, especificidade do conhecimento e o baixo risco de imitação, visto que as organizações não conseguem decifrar facilmente as razões de sucesso dos concorrentes (KUMAR; GANESH, 2011). A produção visa a aquisição de produtos únicos, através da integração do cliente no processo de design, sendo necessário o desenvolvimento de tecnologias e capacitação de recursos capazes de capturar as preferências e necessidades dos consumidores, métodos, ferramentas, sistemas colaborativos informatizados, processo de manufatura sob demanda, flexibilidade na linha de montagem e nos processos de produção, além de integração e harmonizações, entre outros fatores (MOURTZIS; DOUKAS, 2014).

McMahon, Lowe e Culley (2004) abordam o enfoque estratégico da personalização, em que organizações oferecem soluções elevadamente personalizadas para problemas específicos, enfatizam os recursos humanos, a comunicação e o conhecimento compartilhado. Apesar das estratégias de codificação e de personalização serem descritas como distintas, estudos conduzidos por Kumar e Ganesh (2011) revelam que as duas podem ser harmonizadas e complementares, uma vez que o compartilhamento de conhecimento pode ocorrer com o contato direto entre pessoas ou por meio de documento eletrônico.

No campo da liderança, havia a compreensão de que a liderança pode ser um trabalho complexo e exaustivo, cabendo a perspectiva de compartilhar as responsabilidades e reunir competências complementares, aumentando, desta forma, a efetividade de equipes de projetos de alta complexidade (CREVANI; LINDGREN; PACKENDORFF, 2007). Essas autoras

Perspectivas em Gestão \& Conhecimento, João Pessoa, v. 8, número especial, p. 39-54, out. 2018. 
afirmam que a prática já havia sido utilizada na história do Ocidente, desde a antiguidade romana, sendo empregável na atualidade, mesmo que informalmente, em tarefas que envolvam complexidade, criatividade, interdependência e interações entre os membros.

Publicação seminal de Uhl-Bien, Marion e McKelvey (2007), aborda, então, a teoria da liderança complexa. O paradigma da complexidade é adotado, promove rupturas com as teorias tradicionais e evidencia o gerenciamento do emergente (GRAMKOW, 2016). A liderança é tratada não mais como uma posição de autoridade, mas como um processo complexo, emergente, de dinâmica interativa e em rede, o que produz novos padrões de comportamentos e de operação, conforme Uhl-Bien, Marion e McKelvey (2007). A teoria enfoca a exploração de estratégias de três principais funções da liderança: a fundamentada nas noções hierárquicas tradicionais de alinhamento e controle; a função promotora, que estrutura e promove as condições para a criatividade, solução de problemas e aprendizagem; e a função adaptativa, que favorece as dinâmicas e emergência de mudanças. A premissa básica é possibilitar e incentivar a dinâmica informal da rede, promover a criação e captura de conhecimento, aprendizagem e adaptação, em um Sistema Adaptativo Complexo - CAS (UHLBIEN; MARION; McKELVEY, 2007).

Por volta dos anos de 2010 surgem os estudos abordando a liderança mindful, cujo o enfoque reside no estado de consciência do papel de liderança e atenção plena à existência do ser no momento presente (BEVERAGE et al., 2014). A liderança é relacionada à inteligência emocional, visto que os líderes motivam e promovem mudanças por serem percebidos como empáticos, atenciosos, reflexivos, confiáveis, justos e bons articuladores da comunicação.

Uma das mais recentes e discutidas abordagens é a da teoria da liderança relacional. Proposta por Uhl-Bien (2006) na primeira década do corrente século, somente nos últimos anos ela tem apresentado avanços no nível de compreensão teórica e verificação empírica. $A$ abordagem é caracterizada por visão multiparadigmática, incorporando tanto a perspectiva da entidade quanto a construcionista-relacional (OSPINA; UHL-BIEN, 2012). Nessa visão emergente, o conhecimento é construído socialmente e distribuído, em um processo contínuo e sociocultural, que vai além do nível individual (DACHLER; HOSKING, 1995).

\subsection{Síntese das fases de GC e das abordagens de liderança}

Esta seção demonstra as relações entre a evolução das abordagens da liderança com as fases históricas da gestão do conhecimento, conforme sintetizado na Figura 1.

Figura 1 - Relação entre as abordagens de liderança e as fases de GC

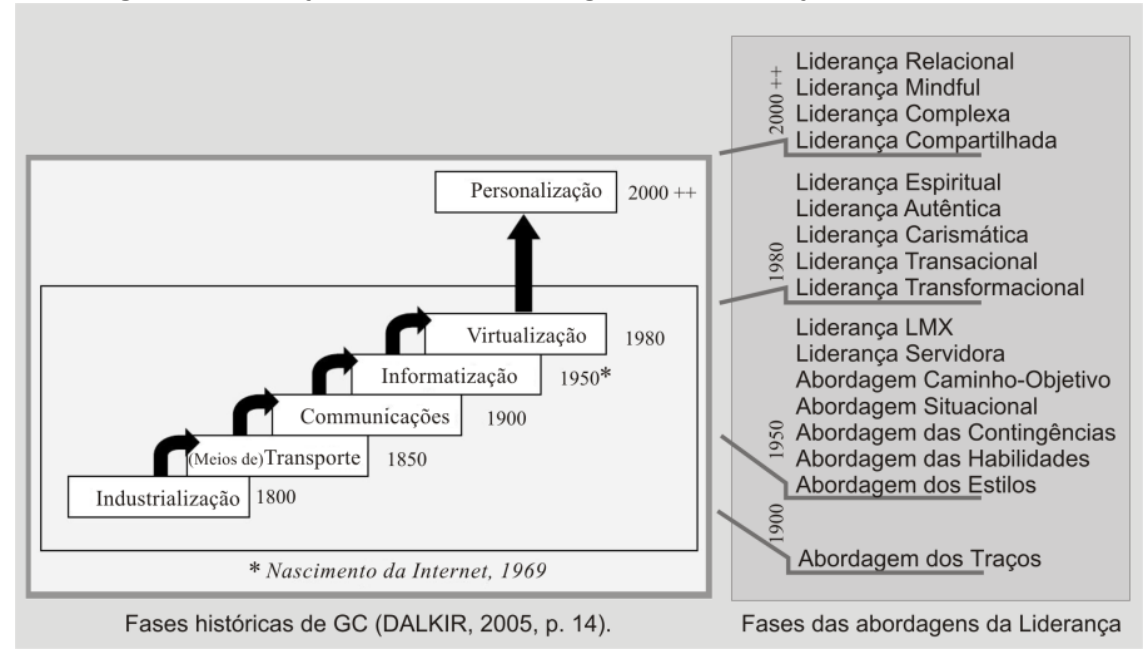

Fonte: Elaborada pelos autores (2018), com base em Dalkir (2005) e revisão da literatura

Perspectivas em Gestão \& Conhecimento, João Pessoa, v. 8, número especial, p. 39-54, out. 2018. 
Outras abordagens podem ser encontradas na literatura sobre liderança, como a liderança distribuída, coletiva, ambidestra. Esta seção não teve o objetivo de exaurir o assunto, mas sim promover o estabelecimento de relações entre as fases da gestão do conhecimento e algumas das principais abordagens da liderança.

\section{CONSIDERAÇÕES FINAIS}

Este estudo possibilitou estabelecer relações entre a evolução das abordagens da liderança com as fases históricas da gestão do conhecimento, considerando a alteração gradativa da cultura organizacional.

Na fase de GC caracterizada como da comunicação é possível verificar que a indústria dos meios de comunicação influenciou a cultura de forma global, promoveu o valor à informação e ao entretenimento da indústria cinematográfica. A fase pode ser interpretada como da espetacularização da pessoa humana, exploração de sua imagem e transformação em mercadoria a ser admirada, como em uma vitrine. É possível relacionar a fase ao desenvolvimento da teoria dos traços, com enfoque nos estereótipos, nos traços, na beleza física, na entidade e em suas características diferenciadoras, seu magnetismo pessoal, e reconhecimento como grande personalidade.

$\mathrm{Na}$ fase de informatização é possível verificar o enfoque na necessidade de desenvolvimento de novas habilidades, de novos comportamentos e capacidades aplicáveis no processo de informatização, emergência de novas realidades organizacionais, enfoque em relações e interações humanas, tecnicidade, mão de obra especializada, trocas, estabelecimento de relações de confiança e gestão do volume de informações. Em contrapartida, nas abordagens da liderança verificou-se o enfoque nas abordagens das habilidades, nos comportamentos orientados para as tarefas ou relacionamentos de qualidade, cooperação, atenção ao treinamento e desenvolvimento humano, autonomia, preparo dos liderados para tomada de decisões, abordagem dos estilos, das contingências, do caminho-objetivo, da liderança situacional, servidora e de trocas relacionais.

$\mathrm{Na}$ fase da virtualização, verificou-se a necessidade de significativas mudanças na cultura organizacional, valor ao elemento humano, estabelecimento de relações de confiança, valor ao compartilhamento de conhecimentos, estruturas em rede, descentralização, parcerias nas trocas comerciais, conversações, adaptabilidade, percepção de pertencimento a comunidades, comprometimento, necessidade de flexibilidade, autogestão e importância ao ambiente de trabalho. Em contrapartida, na literatura sobre liderança identificou-se o enfoque na liderança transformacional, no processo de mudar, desenvolver e transformar pessoas, motivá-las, estimulá-las intelectualmente e empoderá-las. Os envolvidos transformam-se mutuamente, estabelecem trocas e conexões, têm seus esforços reconhecidos, buscam autoconhecimento e espiritualidade no ambiente de trabalho, desenvolvem o senso de pertencimento e cooperação, fazem gestão da informação e conhecimento.

$\mathrm{Na}$ fase de GC caracterizada como da personalização, verificou-se que a gestão do conhecimento enfatizava o processo de personalização com base nas preferências dos clientes internos e externos, desenvolvimento de novos processos de trabalho, comunicação, criatividade, inovação customizada, flexibilidade, repositório e transferência de conhecimentos, adaptação, consideração de elementos humanos e não humanos, alto grau de complexidade, além do enfoque em conhecimentos, harmonizações e complementaridades. Em paralelo, na literatura sobre liderança, o enfoque residiu na liderança complexa, na necessidade de reunir competências complementares e adaptativas, gerenciar o emergente, 0 processual e dinâmico, as interações e comunicação, criatividade, solução de problemas e aprendizagem. Preza-se pela atenção plena do ser, pela inteligência emocional, pela

Perspectivas em Gestão \& Conhecimento, João Pessoa, v. 8, número especial, p. 39-54, out. 2018. 
integração das várias abordagens, em um processo de harmonização e customização da própria liderança.

A principal limitação deste estudo foi a estratégia de busca e de revisão não sistemática da literatura, em função da diversidade dos termos das abordagens citadas, o que tornaria o processo de exploração exaustivo. Desta forma, a linha do tempo identificada de cada abordagem foi feita com base nas referências consultadas. Como sugestão de estudo futuro, recomenda-se a sistematização dos dados de cada abordagem, com identificação de padrões bibliométricos, por meio de estratégia de busca sistemática da literatura.

\section{AGRADECIMENTOS}

Este trabalho recebeu o apoio financeiro parcial da Coordenação de Aperfeiçoamento de Pessoal de Nível Superior - CAPES, o que agradecemos cordialmente. Agradecimentos também aos organizadores do KM Brasil 2018 e à parceria feita com a Revista PG\&C.

\section{REFERÊNCIAS}

ALA - American Library Association's Presidential Committee on Information Literacy: final report. Chicago: American Library Association, 1989. Disponível em: http://www.ala.org/acrl/publications/ whitepapers/presidential. Acesso em jun 2018.

AVALIAÇÃO Quadrienal. Documento de Área: Interdisciplinar. Brasília: Capes, 2016.

BALDISSERA, Rudimar. A teoria da complexidade e novas perspectivas para os estudos de comunicação organizacional. In: KUNSCH, M. M. K. (Org.). Comunicação organizacional: fundamentos e processos, vol.1. São Paulo: Saraiva, 2009. Cap. 7, p. 135-164.

BASS, B. M. Bass \& Stogdill's handbook of leadership: theory, research, and managerial applications. 3rd ed. New York, USA: The Free Press, 1990.

BEVERAGE, S.; DELONG, K.; HEROLD, I. M. H.; NEUFELD, K. Mindful leadership defined and explained. Management and Leadership Innovations Advances in Librarianship, v. 38, p. 2135, 2014. Doi: 10.1108/S0065-283020140000038000.

CREVANI, L.; LINDGREN, M.; PACKENDORFF, J. Shared leadership: a postheroic perspective on leadership as a collective construction. International journal of leadership studies, v. 3, n. 1, p. 40-67, 2007.

CURTIS, M. Introduction to the transaction edition. In: LIPPMANN, W. Public opinion - With a new introduction by Michael Curtis. 2. ed. USA: Transaction Publishers, 1998, p. xi - xxxvi.

DACHLER, P.; HOSKING, D-M. The primacy of relations in socially constructing organizational realities. In: HOSKING, D. M.; DACHLER, H. P.; GERGEN, K. J. (Eds.). Management and Organisation: Relational Perspectives. Ashgate/Avebury, 1995.

DALKIR, K. Knowledge management in theory and practice. USA: Elsevier, 2005.

Perspectivas em Gestão \& Conhecimento, João Pessoa, v. 8, número especial, p. 39-54, out. 2018. 
DEBORD, G. Society of the spectacle. Authorised translation by Ken Knabb. London: Rebel Press, 2005.

DUBOIS, N.; WILKERSON, T. Knowledge management: background paper for the development of a knowledge management strategy for public health in Canada. Hamilton: National Collaborating Centre for Methods and Tools, 2008.

FAIRHOLM, G. W. Perspectives on leadership: from the science of management to its spiritual heart. USA: Greenwood Publishing Group, 1998.

FIEDLER, F. E. The contingency model: A theory of leadership effectiveness. In: LEVINE, J. M.; MORELAND, R. L. (Eds.). Small groups: key readings. New York: Psychology Press, 2006, p. 369381.

FORBES, D. A. An example of the use of systematic reviews to answer an effectiveness question. Western Journal of Nursing Research, 2003, v. 25, n. 2, p. 179-192, 2003.

FRANKE, U. The knowledge-based view (KBV) of the virtual web, the virtual corporation, and the net-broker. In: MALHOTRA, Y. (Ed.). Knowledge management and virtual organizations. USA: Idea Group Publishing, 2000, p. 20-42.

GIORDANO, L. Beyond Taylorism: computerization and the new industrial relations. USA: St. Martin's Press, 1992.

GRAEN, G. B.; UHL-BIEN, M. Relationship-based approach to leadership: development of leader-member exchange (LMX) theory of leadership over 25 years: applying a multi-level multi-domain perspective. Leadership Quarterly, v. 6, n. 2, p. 219-247, 1995.

GRAMKOW, F. B. Liderança complexa em uma equipe de desenvolvimento de software. 212p. Tese (Doutorado em Engenharia e Gestão do Conhecimento) - Programa de PósGraduação em Engenharia e Gestão do Conhecimento, Universidade Federal de Santa Catarina, Florianópolis, 2016.

HEIFETZ, R. A. Leadership without easy answers. London, England: Belknap- Harvard, 1994. Cap.3, The roots of authority.

KLING, R. Learning about information technologies and social change: the contribution of social informatics. Information Society, v. 16, n. 3, p. 217-232, 2000 . doi 10.1080/01972240050133661

KRAUSE, M.G. Marketing interno em apoio às práticas de gestão do conhecimento em organizações de base tecnológica. 185p. Dissertação (Mestrado em Engenharia e Gestão do Conhecimento) - Programa de Pós-Graduação em Engenharia e Gestão do Conhecimento, Universidade Federal de Santa Catarina, Florianópolis, 2014.

KUMAR, J. A.: GANESH, L. S. Balancing knowledge strategy: codification and personalization during product development. Journal of Knowledge Management, v.15, n. 1, p.118-135, 2011. https://doi.org/10.1108/13673271111108738. 
LAVOIE, M.; THERRIEN, P. Different strokes for different folks: examining the effects of computerization on Canadian workers. Technovation, v. 25, p. 883-894, 2005.

LEMKEN, B.; KAHLER, H.; RITTENBRUCH, M. Sustained knowledge management by organizational culture. Proceedings of the 33rd Hawaii International Conference on System Sciences, 2000.

LIPPMANN, W. Public opinion - With a new introduction by Michael Curtis. 2 ed. USA: Transaction Publishers, 1998.

MACEDO, M. et al. Gestão do conhecimento organizacional. Florianópolis: Ed. da UFSC, 2010.

MARTINO, L. M. S. Teoria da comunicação: ideias, conceitos e métodos. 4ạ ed. Revista e atualizada. Petrópolis, RJ: Vozes, 2013.

McMAHON, C.; LOWE, A.; CULLEY, S. Knowledge management in engineering design: personalization and codification. Journal of Engineering Design, v. 15, n. 4, p. 307-325, 2004. doi: 10.1080/09544820410001697154

MONTGOMERY, A. L.; SMITH, M. D. Prospects for personalization on the internet. Journal of Interactive Marketing, v. 23, n. 2, p. 130-137, 2009. doi: 10.1016/j.intmar.2009.02.001

MORGAN, G. Paradigms, metaphors, and puzzle solving in organization theory. Administrative Science Quarterly, v. 25, n. 4, p. 605-622, 1980.

MOURTZIS, D.; DOUKAS, M. Design and planning of manufacturing networks for mass customisation and personalisation: challenges and Outlook. Proceedings: 2nd CIRP Robust Manufacturing Conference (RoMac), 2014. Bremen, Germany: Procedia CIRP, v. 19, p. 1-13, 2014. doi: $10.1016 /$ j.procir.2014.05.004

MUMFORD, M. D.; ZACCARO, S. J.; HARDING, F. D.; JACOBS, T. O.; FLEISHMAN, E. A. Leadership skills for a changing world: solving complex social problems. The Leadership Quarterly, v. 11, n. 1, p. 11-35, 2000.

NORTHOUSE, P. G. Leadership: theory and practice. 6th. ed. Thousand Oaks, CA: Sage Publications, 2013.

OSPINA, S. M.; UHL-BIEN, M. Mapping the terrain: Convergence and divergence around relational leadership. In: UHL-BIEN, M.; OSPINA, S. (Ed.). Advancing relational leadership research: a dialogue among perspectives. USA: Information Age Publishing, 2012.

SCHEIN, E. H. Organizational culture and leadership. 3rd ed. San Francisco, CA: Jossey-Bass, 2004.

STANKOSKY, M. A. Advances in knowledge management: University research toward an academic discipline. In: STANKOSKY, M. (Ed.). Creating the discipline of knowledge management: The latest in university research. USA: Elsevier Butterworth-Heinemann, 2005. p. 1-14.

Perspectivas em Gestão \& Conhecimento, João Pessoa, v. 8, número especial, p. 39-54, out. 2018 
SVEIBY, K. E. A nova riqueza das organizações: gerenciando e avaliando patrimônios de conhecimento. Tradução de Luiz Euclydes Trindade Frazão Filho. Rio de Janeiro: Campus, 1998.

TAKEUCHI, H.; NONAKA, I. Gestão do conhecimento. Tradução Ana Thorell. Porto Alegre: Bookman, 2008.

TORRACO, R. J. Writing integrative literature reviews: guidelines and examples. Human Resource Development Review, v. 4, n. 3, p. 356-367, 2005. Doi: 10.1177/1534484305278283

TRANFIELD, D.; DENYER, D.; SMART, P. Towards a methodology for developing evidenceinformed management knowledge by means of systematic review. British Journal of Management, v. 14, p. 207-222, 2003.

UHL-BIEN, M. Relational leadership theory: exploring the social processes of leadership and organizing. Leadership Quarterly, v. 17, p. 654-676, 2006.

UHL-BIEN, M.; MARION, R.; MCKELVEY, B. Complexity leadership theory: shifting leadership from the industrial age to the knowledge era. Leadership Quarterly, v. 18, p. 298-318, 2007.

WIIG, K. M. People-focused knowledge management: how effective decision making leads to corporate success. USA/UK: Elsevier, 2004.

YUKL, G. A. Leadership in organizations. 6th ed. New Jersey, USA: Pearson Prentice Hall, 2006. 